\title{
СОПОСТАВЛЕНИЕ РЕАКЦИЙ ЭЛЕКТРОФИЛЬНОГО ПРИСОЕДИНЕНИЯ. ОБРАЗОВАНИЕ ЦИКЛИЧЕСКИХ ПРОДУКТОВ
}

\author{
(Представил К. Лээтс)
}

Реакции электрофильного присоединения к ненасыщенным соединениям часто сопровождаются побочными процессами. Так, $\alpha$-алкильные заместители по отношению к двойной связи алкена способствуют депротонированию катионного интермедиата, а $\beta$-алкильные заместители - внутримолекулярным гидридным или алкильным сдвигам [']. В настоящем обзоре более обстоятельно рассмотрены закономерности образования циклических продуктов, главным образом при катионном присоединении галогенов и галогенопроизводных к алкенам и алкинам, а также при катионной полимеризации алкенов.

Согласно общепринятым представлениям, в реакциях электрофильного присоединения к алкенам в лимитирующей стадии образуются интермедиаты карбокатионного типа, которые, вследствие высокой активности, могут взаимодействовать с различными молекулами или частицами электронодонорного характера. Например $\left[{ }^{2-6}\right]$ :

1) с ненасыщенными связями алкенов, алкинов или аренов (приводит к высшим (полимерным) продуктам или продуктам алкилирования);

2) с группами, имеющими неподеленные электронные пары (часто HO-, HN-, HS-содержащие растворители, образующие смешанные продукты);

3) с а к ти в ы и и связями углерод-галоген или углерод-водород (реакции переноса реакционной цепи при процессах теломеризации или алкилирования алканов);

4) с анғонами (реакции рекомбинации или депротонирования).

В таблице систематизированы типичные примеры образования циклических продуктов в процессах катионного присоединения. Эти данные показывают аналогию при взаимодействии катионного центра с нуклеофилом меж- или внутримолекулярно. Межмолекулярные реакции приводят к регулярным продуктам, внутримолекулярные - к изомерным.

Типичные внутримолекулярные взаимодействия изображены на следующей схеме $\left(X=\mathrm{Hlg} ; X M X_{n}^{-}=\operatorname{Zn} X_{3}^{-}, \operatorname{Sn} X_{5}^{-}\right.$и. т. п. или $X_{3}^{-} ; \quad Y=\mathrm{H}$, Alk, Ar) : 


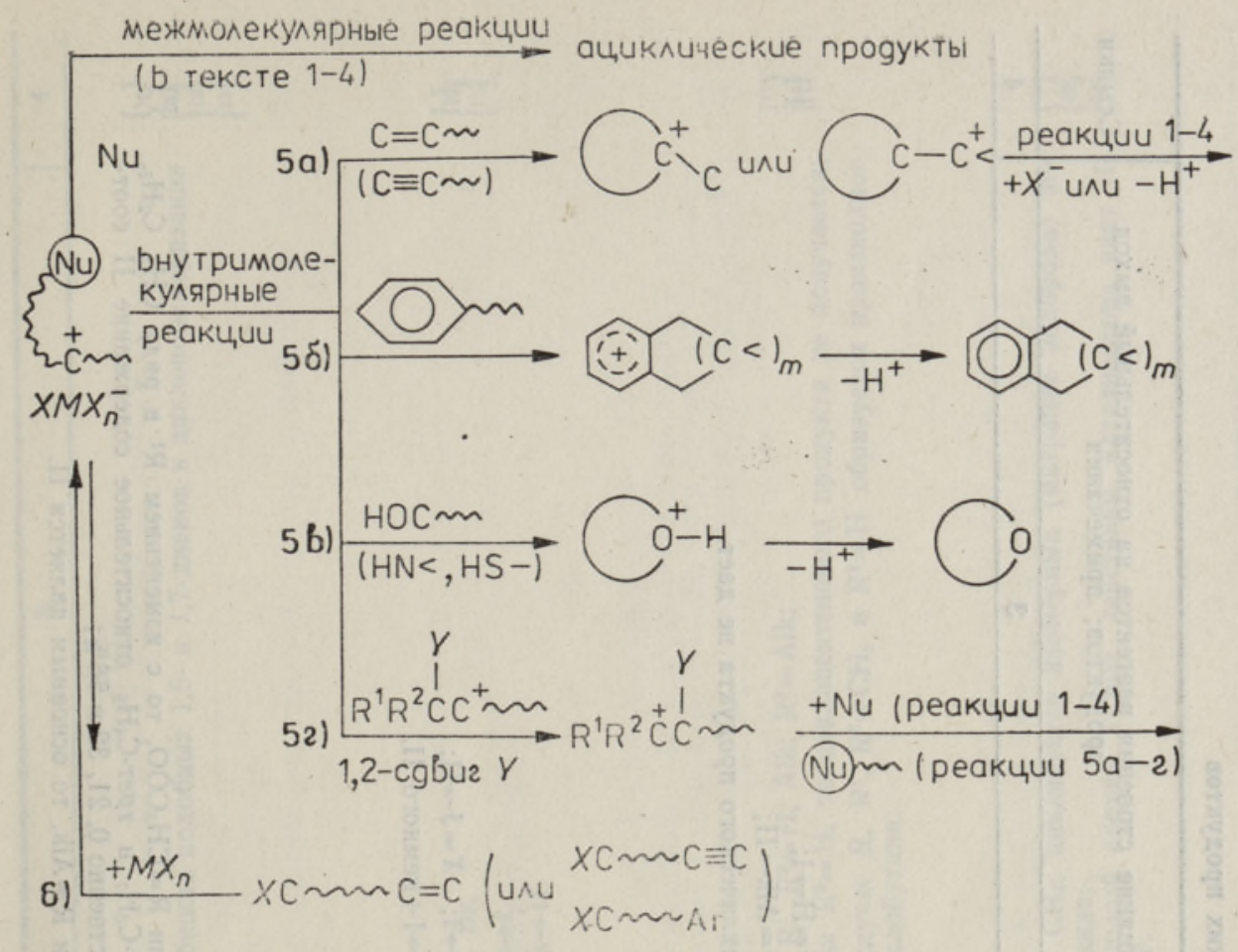

Реакции внутримолекулярного присоединения по кратным связям или по электронодонорным группам дают карбо- или гетероциклические изомеры, а реакции внутримолекулярного переноса водорода или алкильных групп дают ациклические изомеры - продукты 1,1- или 1,3присоединения ['].

Необходимым условием циклоприсоединения является наличие реак-

ционноспособной группы

(Nu) в стерически подходящем поло-

жении от катионного центра (см. ниже). Эта реакционноспособная группа или присутствует в молекуле исходного алкена, или внедряется присоединением карбониевого катиона к алкену (теломеризация, полимеризация). В зависимости от химического характера группы

Noun eе взаимодействие с катионным центром приводит к

циклическому интермедиату, который дальше, при реакции с нуклеофилом $\mathrm{Nu}$, либо депротонируется (направления $5 \mathrm{a-B}$ ), либо присоединяет анион (направление 5а).

В таблице приведены также данные об относительном выходе продуктов. На их основе можно вывести некоторые закономерности влияния стерических и электронных факторов и условий проведения процесса на относительную скорость циклизации.

Из стерических факторов, термодинамические аспекты которых рассмотрены в [17,54], циклизации способствуют:

a) наличие реакционноспособного нуклеофильного центра в положениях 5 или 6 по отношению к катионному центру, что приводит к наиболее выгодным 5- или 6-членным циклам. Легкость циклизации в зависимости от числа звеньев в цикле падает в следующем ряду [ ${ }^{55}$ ]: $6>5$, $7>8>4,9,10,11$; 


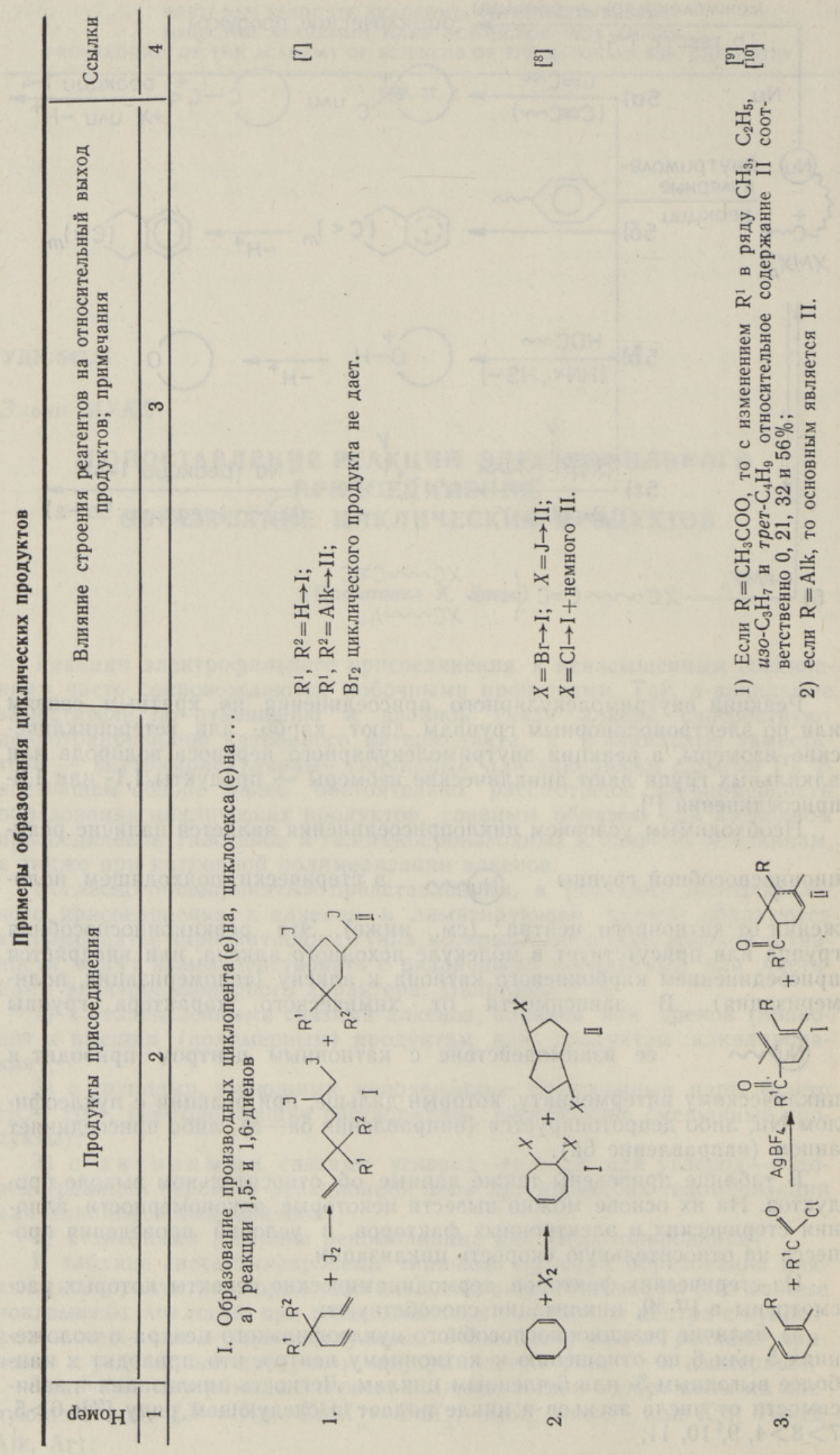




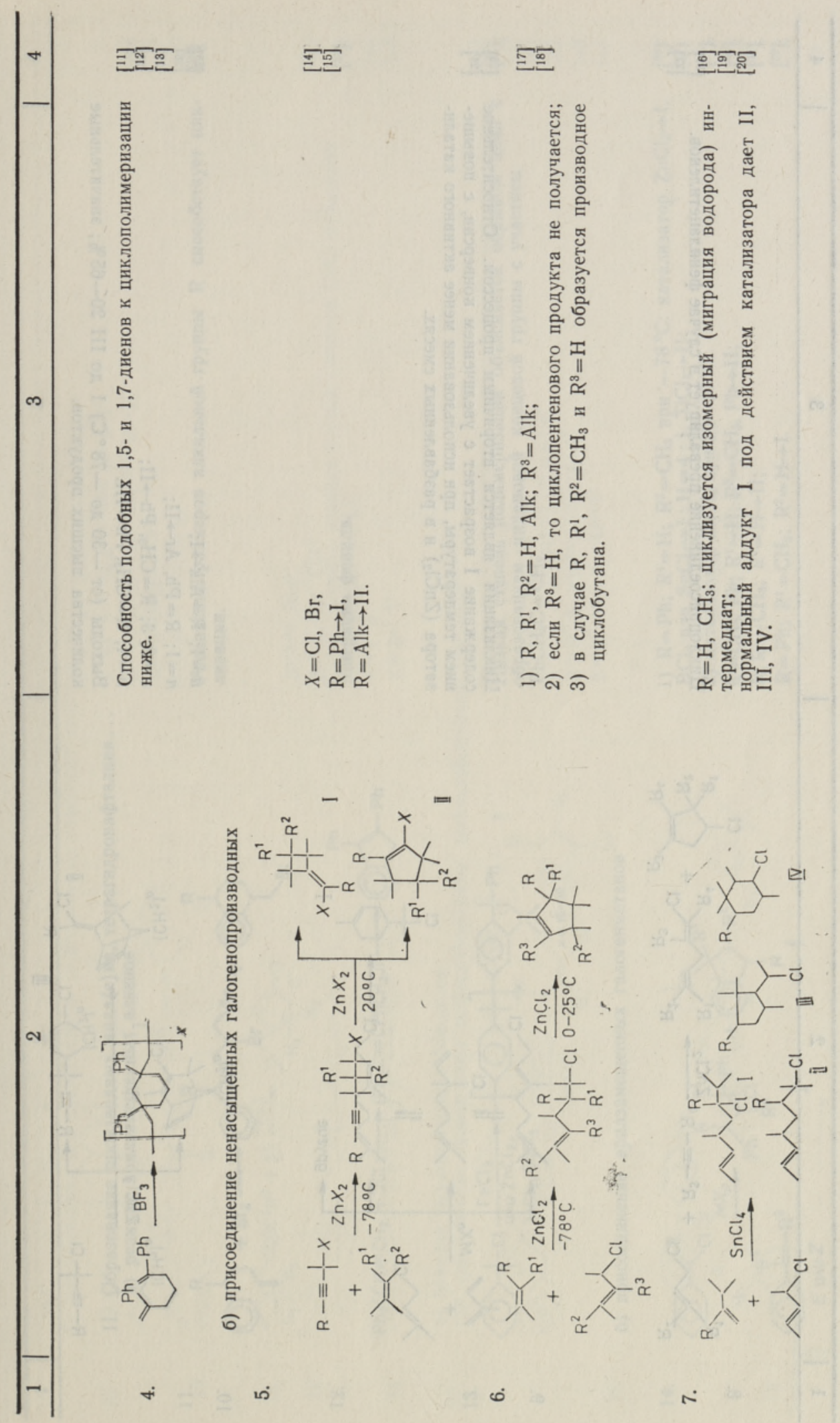




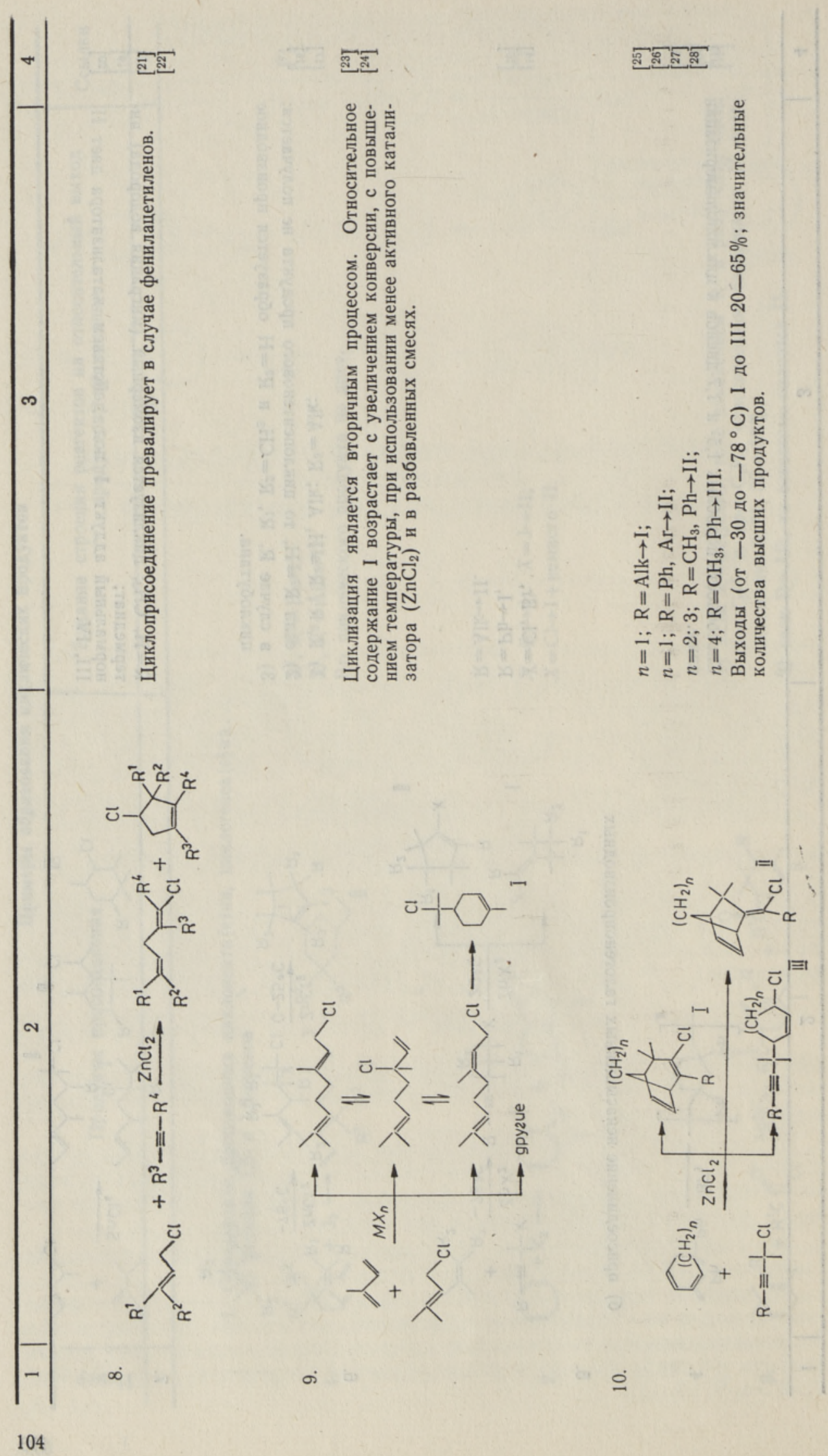




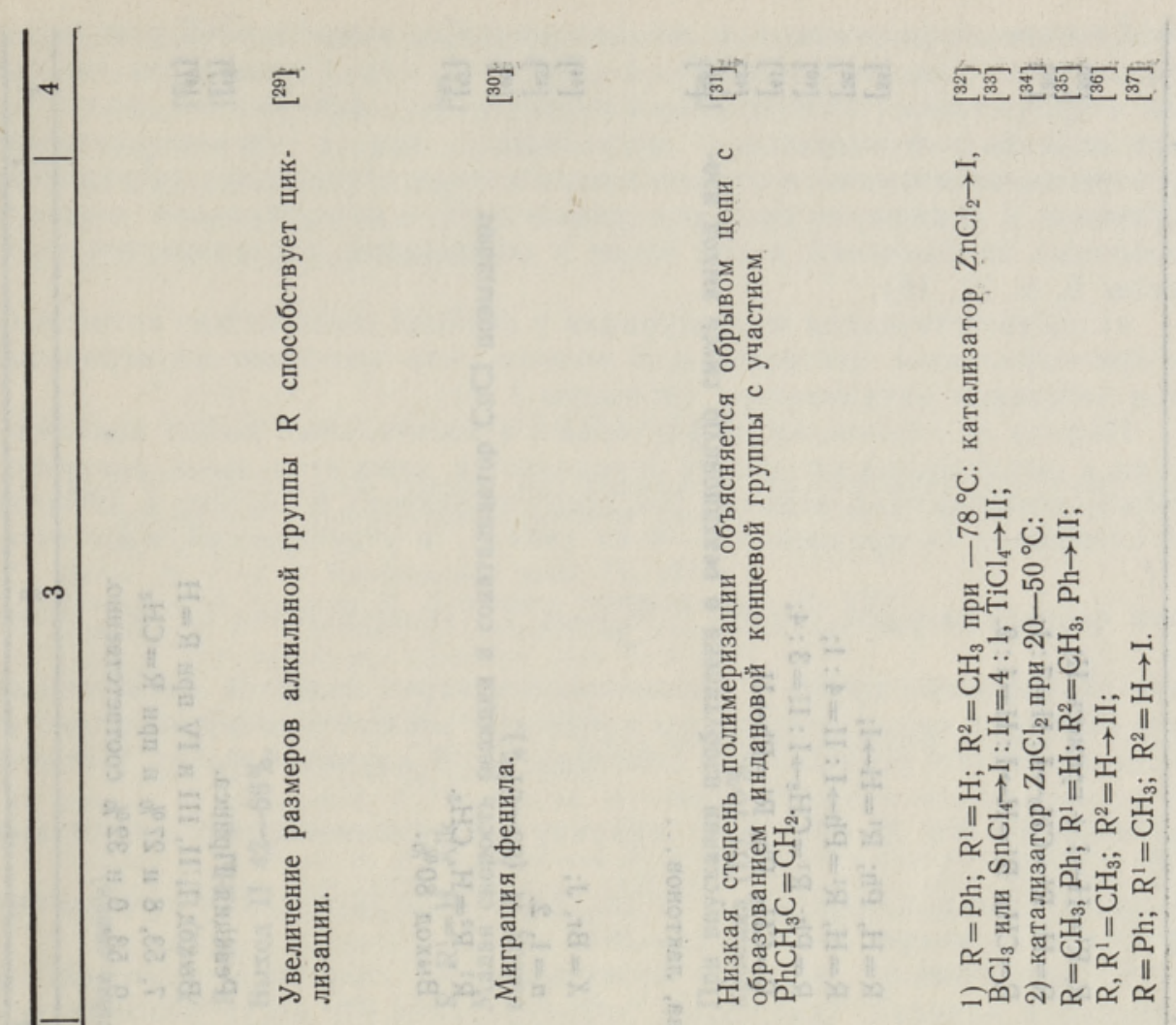

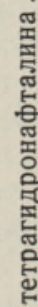
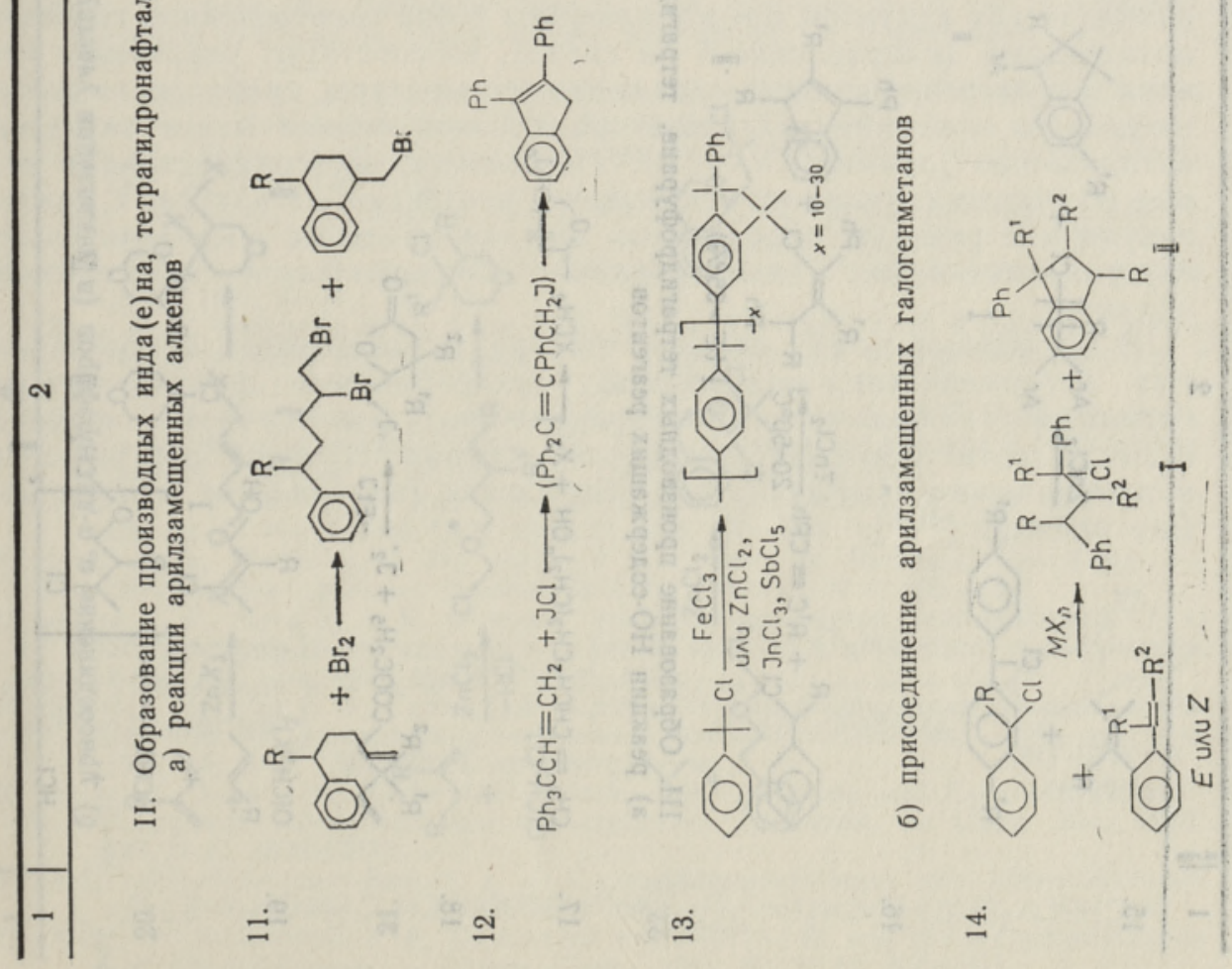


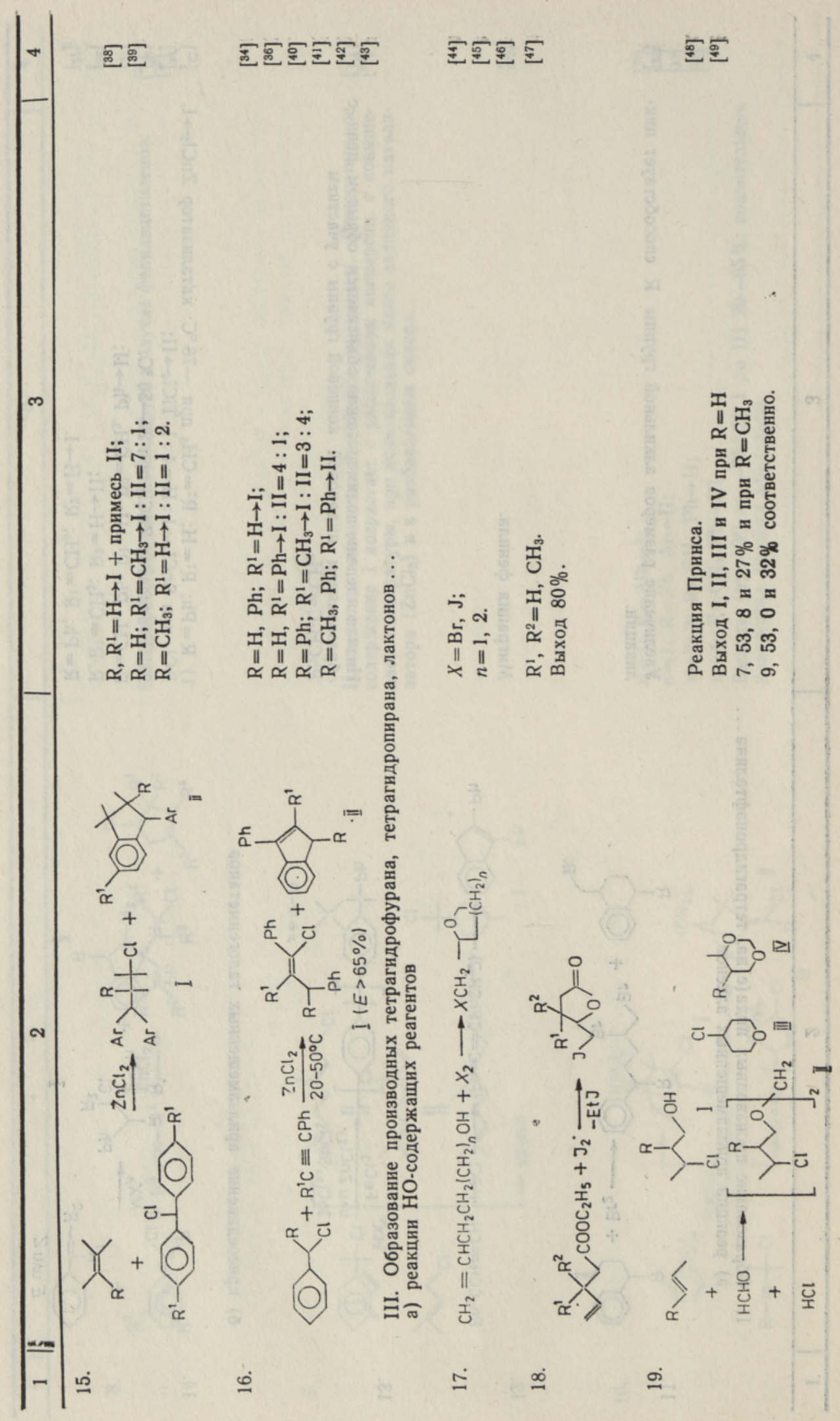




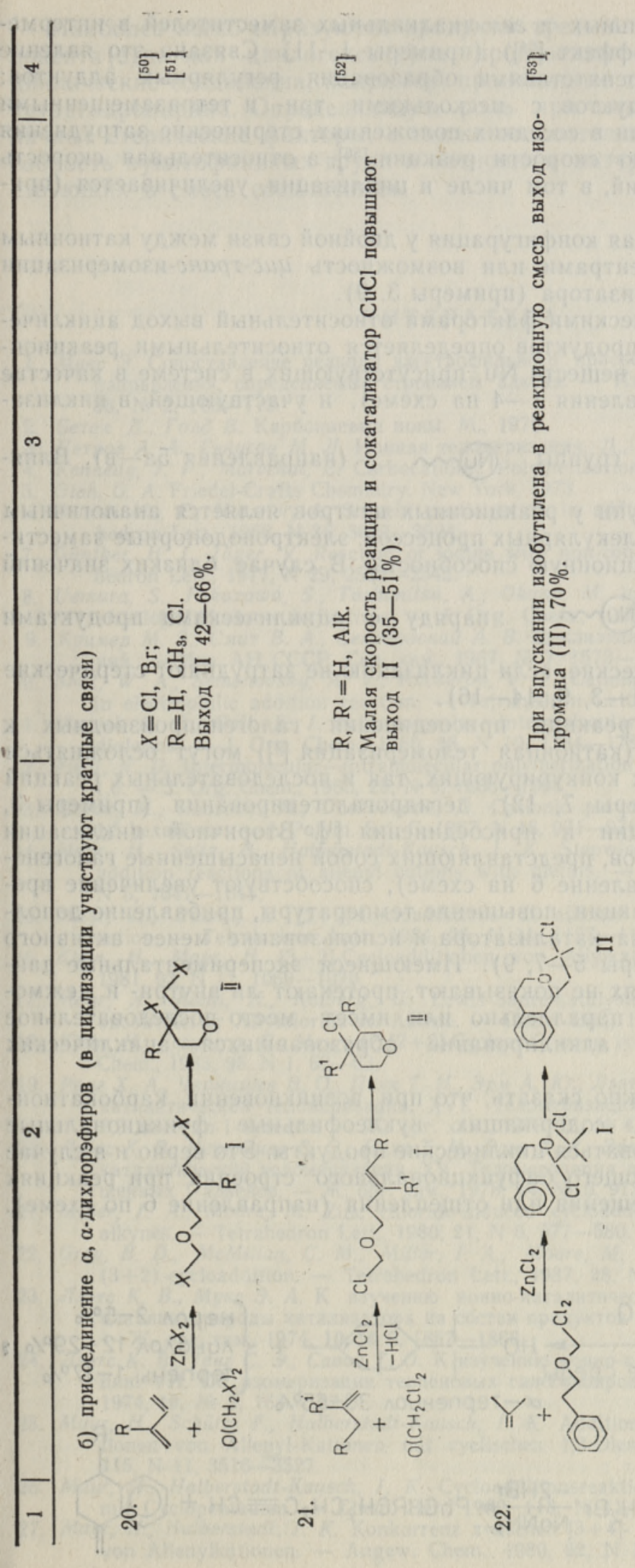


б) наличие алкильных и гем-диалкильных заместителей в интермедиате (гем-диалкилэффект $\left.\left[{ }^{54}\right]\right)$ (примеры 1, 11). Связано это явление со стерическими препятствиями образования регулярных аддуктов: при образовании аддуктов с несколькими три- и тетразамещенными углеродными атомами в соседних положениях стерические затруднения приводят к снижению скорости реакции $\left[{ }^{56}\right]$, а относительная скорость побочных направлений, в том числе и циклизации, увеличивается (примеры $5,6,14,15)$;

в) соответствующая конфигурация у двойной связи между катионным и нуклеофильным центрами или возможность цисс-транс-изомеризации под действием катализатора (примеры 3,9 ).

Наряду со стерическими факторами относительный выход ациклических и циклических продуктов определяется относительными реакционными способностями веществ $\mathrm{Nu}$, присутствующих в системе в качестве нуклеофилов (направления $1-4$ на схеме), и участвующей в циклиза-

\section{ции функциональной группы (uㅡ (направления 5а-в). Влия-}

ние замещающих групп у реакционных центров является аналогичным для внутри- и межмолекулярных процессов: электронодонорные заместители повышают реакционную способность. В случае близких значений активностей $\mathrm{Nu}$ и Num наряду с ациклическими продуктами

получаются и циклические, если циклизацию не затрудняют стерические факторы (примеры $1-3,9,14-16)$.

Каталитические реакции присоединения галогенопроизводных к алкенам и алкинам (катионная теломеризация [3]) могут осложняться из-за протекания как конкурирующих, так и последовательных реакций изомеризации (примеры 7, 12), дегидрогалогенирования (примеры 3 , $12,13,21)$, циклизации и присоединения [1]. Вторичной циклизации ациклических аддуктов, представляющих собой ненасыщенные галогенопроизводные (направление 6 на схеме), способствуют увеличение времени и конверсии реакции, повышение температуры, прибавление дополнительного количества катализатора и использование менее активного катализатора (примеры $5-7,9$ ). Имеющиеся экспериментальные данные во многих случаях не показывают, протекают ли внутри- и межмолекулярные реакции параллельно или имеет место последовательное внутримолекулярное алкилирование образовавшихся ациклических аддуктов.

В заключение можно сказать, что при возникновении карбокатионных интермедиатов, содержащих нуклеофильные функциональные группы, могут образоваться циклические продукты. Это верно и в случае веществ соответствующего бифункционального строения при реакциях нуклеофильного замещения или отщепления (направление 6 по схеме). Два примера $\left[{ }^{29,57]:}\right.$

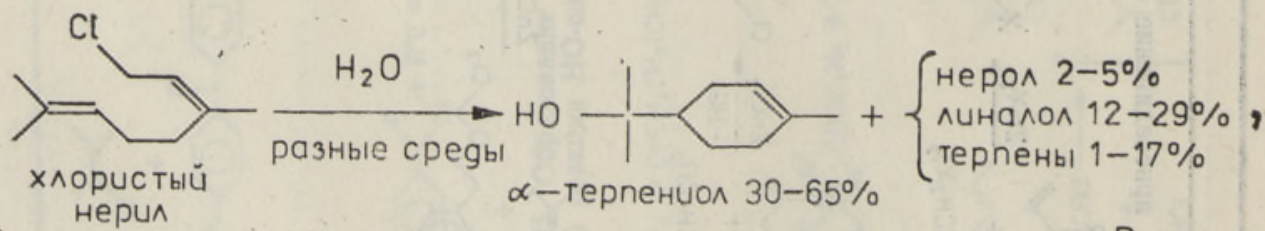

$$
\mathrm{PhCHRCH} \mathrm{CH}_{2} \mathrm{CHBrCH}_{2} \mathrm{Br} \frac{-2 \mathrm{HBr}}{\mathrm{NaNH}_{2}} \mathrm{PhCHRCH}_{2} \mathrm{CH}_{2} \mathrm{C} \equiv \mathrm{CH}
$$


Наиболее легко образуются продукты трех типов: производные циклопента (e) на или циклогекса (e)на, производные инда (е)на и гетероциклические соединения, например, производные тетрагидрофурана или тетрагидропирана. Определяющую роль при циклизации играют различные стерические факторы, а также относительная реакционная способность нуклеофильных групп в катионном интермедиате и в присутствующих в смеси соединениях,

\section{ЛИТЕ РА Т У РА}

1. Мукс Э. Сопоставление реакций электрофильного присоединения. Конкурирующие направления, определяемые строением алкена. - Изв. АН ЭССР. Хим., 1987, 36 , № 2, 103-113.

2. Бетел Д., Голд В. Карбониевые ионы. М., 1970.

3. Петров А. А., Генусов М. Л. Ионная теломеризация. Л., 1968.

4. Kennedy, J. P., Marechal, E. Carbocationic Polymerization. New York, 1982.

5. Olah, G. A. Friedel-Crafts Chemistry. New York, 1973.

6. Boerwinkle, F., Hassner, A. Solvent participation in additions to olefins. - Tetrahedron Lett., 1968, N 36, 3921-3924.

7. Günther, $H . J ., J a g g e r, V$. Reaction of iodine with non-conjugated dienes. - Tetrahedron Lett., 1977, N 29, 2539-2542.

8. Uemura, S., Fukuzawa, S., Toshimitsu, A., Okano, M. Iodine-induced formation of bicyclo[3.3.0]octane derivatives. - J. Org. Chem., 1983, 48, N 2, 270-273.

9. Кример М. 3., Смит В. А., Семеновский А. В. Циклизация изопреноидных соединений. - Изв. АН СССР. Сер. хим., 1967, № 7, 1573-1979; 1968, № 4, 866-874.

10. Smit, W. A., Semenovsky, A. V., Kucherov, V. F. Cationoid complexes as reagents in electrophilic addition reaction. - Tetrahedron Lett., 1971, N 33, 3101-3106.

11. Marvel, C. S., Gall, E. J. Intramolecular-intermolecular polymerizations of some diolefins. - J. Org. Chem., 1960, 25, N 10, 1784-1786.

12. Field, $N$. D . Intermolecular-intramolecular polymerization of 2,6-diphenylheptadiene1,6. - J. Org. Chem., 1960, 25, N 6, 1006-1008.

13. Marek. M., Roosova, M., Doskočilova, D. Cationic polymerization of 2,5-dimethyl1,5-hexadiene. - J. Polym. Sci. C, 1967, N 16, 971-976.

14. Mayr, H., Seitz, B., Halberstadt-Kausch, I. K. Stepwise $[2+2]$ and $[3+2]-c y c l o-$ addition reactions of allenyl cations with olefins. - J. Org. Chem., 1981, 46, N $5,1041-1043$.

15. Mayr, H., Bäuml, E. [2+2]-Cycloadditions of alkenes with the triphenylallenyl cation. - Tetrahedron Lett., 1984, 25, N 11, 1127-1130.

16. Klein, H., Mayr, H. [3+2]-Cycloadditionen von Allylkationen. - Angew. Chem., $1981,93, \mathrm{~N} 12,1069-1070$.

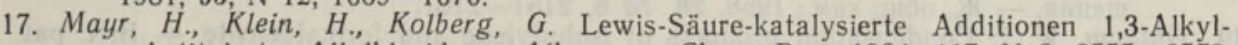
substituierter Allylkloride an Alkene. - Chem. Ber., 1984, 117, N 8, 2555-2579.

18. Klein, H., Freyberg, G., Mayr, H. [2+2]-Cycloadditionen von Allylkationen. - Angew. Chem., 1983, 95, N 1, 62-63.

19. Ране Х. А., Чернышев В. О., Пехк Т. И., Эрм А. Ю., Лээтс К. В. К изучению ионнокаталитической теломеризации. XVI. Теломеризация 2-хлор-транс-3-пентена с 2,3-диметил-1-бутеном. - Ж. орг. хим., 1979, 15, № 4, 686-691.

20. Лээтс К. В., Чернышев В. О., Пехк Т. И., Ранг Х. А., Эрм А. Ю. К изучению ионнокаталитической теломеризацин. XV. Теломеризащия гем-диалкил и $\beta$-алкилзамещенных 1-алкенов. - Ж. орг. хим., 1978, 14, № 5, 913-920.

21. Miller, J. A., Moore, M. Zinc chloride-induced cycloaddition of allyl chlorides to alkynes, - Tetrahedron Lett., 1980, 21, N 6, 577-580.

22. Grey, B. D., McMillan, C. M., Miller, J. A., Moore, M. Bicyclo[3,2,1]oct-6-enes via $(3+2)$-cycloaddition. - Tetrahedron Lett., 1987, 28, N 2, 235-238.

23. Лээтс К. В., Мукс Э. А. К изучению ионно-каталитической теломеризации. IX. О влиянии природы катализатора на состав продуктов и кинетику теломеризации. -Ж. орг. хим., 1974, 10, № 9, 1857-1860.

24. Лээтс К. В., Тенг С. Э., Савич T. О. К изучению ионно-каталитической теломеризации. VII. Об изомеризации терпеновых галогенопроизводных. - Ж. орг. хим., 1974, 10, № 2, $164-167$.

25. Mayr, H., Schütz, F., Halberstadt-Kausch, J. K. Additions und Cycloadditionsreaktionen von Allenyl-Kationen mit cyclischen 1,3-Dienen, - Chem. Ber., 1982, 115, N 11, 3516-3527.

26. Mayr, H., Halberstadt-Kausch, J. K. Cycloadditionsreaktionen von Allenyl-Kationen mit Cyclopentadien. - Chem. Ber., 1982, 115, N 11, 3479-3515.

27. Mayr, H., Halberstadt, J. K. Konkurrenz zwischen $[3+4]$ - und $[2+4]$-Cycloadditionen yon Allenylkationen. - Angew. Chem., 1980, 92, N 10, 840-841. 
28. Mayr, H., Schütz, F. Addition and cycloaddition reactions of allenyl cations with various cycloalka-1,3-dienes. - Tetrahedron Lett., 1981, 22, N 10, 925-928.

29. Caporusso, A. M., Lardicci, $L$. An unusual cyclization of 5-phenylalk-1-enes with bromine. - J. Chem. Res., Synop., 1983, N 8, 194-195.

30. Hassner, A., Teeter, J. S. Phenyl migration in pseudohalogen additions to 3,3,3-triphenylpropene. - J. Org. Chem., 1970, 35, N 10, 3397-3401.

31. Fritz, A., Rees, R. W. Synthesis of aryleneisopropylidene polymers. - J. Polym. Sci., Part A-1, 1972, 10, N 8, 2365-2378.

32. Pock, R., Mayr, H., Rubow, M., Wilhelm, E. Do carbenium ion additions toward alkenes proceed via $\pi$-complexes? A stereochemical investigation. - J. Amer. Chem. Soc., 1986, 108, N 24, 7767-7772.

33. Marcuzzi, F., Melloni, G. Synthesis and configuration of 1,2,3-triphenyl- and 1,3-diphenyl-2-methylindans. - J. Chem. Res., Synop., 1979, N 6, 184-185.

34. Marcuzzi, F., Melloni, G., Modena, G. Electrophilic additions to acetylenes. - J. Org. Chem., 1979, 44, N 17, 3022-3028.

35. Mayr, H., Striepe, W. Scope and limitations of aliphatic Friedel-Crafts alkylations, - J. Org. Chem., 1983, 48, N 8, 1159-1165.

36. Marcuzzi, F., Melloni, G. Electrophilic additions to acetylenes. - Tetrahedron Lett., $1975, \mathrm{~N} 32,2771-2774$.

37. Marcuzzi, F., Melloni, G. Sintesi e caracterizzazione di indani 1,2,3-trifenil- e 1,3-difenil-2-metilsostituti. - Chem. Ind. (Milan), 1976, 58, N 10, 731-732.

38. Mayr, H., Pock, R. Relative Reaktivität Alkyl-substituierter Alkene und Cycloalkene gegenüber Diarylcarbenium-Ionen. - Chem. Ber., 1986, 119, N 8, 2473-2496.

39. Mayr, H., Pock, R. Relative reactivities of alkenes toward diphenylmethyl cation. Tetrahedron Lett., 1983, 24, N 21, 2155-2158.

40. Maroni, R., Melloni, G., Modena, G. Addition of alkyl chlorides to diphenylacetylene. - J. Chem. Soc. Perkin Trans. I, 1974, N 3, 353-356.

41. Maroni, R., Melloni, G. Formation of indenes by addition of carbonium ions to diphenylacetylene. - Tetrahedron Lett., 1972, N 28, 2869-2870.

42. Maroni, R., Melloni, G., Modena, G. Addition of alkyl chlorides to phenylacetylene. J. Chem. Soc. Perkin Trans. I, 1973, N 21, 2491-2496.

43. Marcuzzi, F., Melloni, G. Electrophilic additions to acetylenes. VI. Addition of $t$-butyl chloride and benzyl chloride to alkynes. - J. Chem. Soc. Perkin Trans. II, 1976, N 13, 1517-1522.

44. Williams, D. L. H. Participation by the hydroxyl group in the addition of iodine to unsaturated alcohols. - Tetrahedron Lett., 1967, N 21, 2001-2002.

45. Williams, D. L. H., Bienvenüe-Goetz, E., Dubois, J. E. Participation by neighbouring groups in addition reactions. - J. Chem. Soc. (B), 1969, N 5, 517.

46. Ренгевич E. Н., Станинец В. Н., Шилов Е. А. К вопросу о значении циклических переходных комплексов в механизме органических реакций. - Докл. АН СССР, 1962, 146, № 1, 111-114.

47. Jäger, V., Günther, $H$. J. Synthesis of $\gamma$-methylene butyrolactones (4-penten-4-olides). - Tetrahedron Lett., 1977, N 29, 2543-2546.

48. Фарберов М. И., Сперанская В. А. Синтез $\beta$-хлорзамещенных спиртов и их превращения. - Ж. общ. хим., 1958, 28, № 8, 2151-2161.

49. Oldham, W. J. Condensation products of isobutylene and formaldehyde. - Brit. pat. 775357, 1957; Chem. Abstrs., 1957, 51, 15112.

50. Геворкян А. А., Баданян Ш. О., Казарян П. И. Реакция бнс-( $\alpha$-галоидированных) эфнров с бутадиеном-1,3. - Арм. хнм. ж., 1972, 25, № 5, 426-430.

51. Вартанян С. А., Геворкян Ш. А., Дангян Ф. В. Реакция циклизацин 1,3-диенов с бис- ( $\alpha$-хлоралкиловыми) эфирами. - Изв. АН Арм. ССР. Хим. науки, 1962, 15, № $3,259-262$.

52. Геворкян А. А., Баданян Ш. О., Манукян А. А., Казарян П. И. Реакция бис-хлорметилового эфира с олефинами. Синтез тетрагидропиранов. - Арм. хим. Ж., 1971, 24, № 10, 909-912.

53. Ducshek, C., Muehlstaedt, M., Mueller, K. 1-Substituted isochromans. - Ger. (East) pat. 141 159, 1980; Chem. Abstrs., 1981, 94, 174884.

54. Allinger, N. L., Zalkow, V. The gem-dimethyl effect. - J. Org. Chem., 1960, 25, N 5, $701-704$.

55. Allinger, N. L., Tribble, M. T., Miller, M. A., Wertz, D. H. An improved force field for the calculation of the structures and energies of hydrocarbons. - J. Amer. Chem. Soc., 1971, 93, N 7, 1637-1649.

56. Мукс Э. А., Эрм А. Ю., Лыйвеке И. А., Тенг С. Э., Крумм Л. Л., Лээтс К. В. К изучению ионно-каталитической теломеризации. XXV. Стернческнй эффект алкильных заместителей. - Ж. орг. хим., 1988 (в печати).

57. Тенг $C$., Лээтс $K$. О реакциях превращения терпеновых галогенопронзводных аллильного строения в оксипронзводные. - Изв. АН ЭССР. Хим. Геол., 1971, 20, № 4, 322-327.

\section{Ннститут химии}

Академии наук Эстонской ССР
Поступила в редакцию 20/XI 1987 


\section{ELEKTROFIILSED OHINEMISREAKTSIOONID. TSUKLILISTE PRODUKTIDE MOODUSTUMINE}

On klassifitseeritud rida tsükliliste produktide moodustumise näiteid halogeenide ja halogeeniderivaatide katioonsetes ühinemisreaktsioonides alkeenide vōi alküünidega. On välja toodud mõningad tsüklisatsiooni seaduspärasused. Katioonse tsentri intra- ja intermolekulaarsed reaktsioonid nukleofiilse tsentriga toimuvad sarnaselt.

\section{Elvi MUKS}

\section{COMPARISON OF ELECTROPHILIC ADDITION REACTIONS.} CYCLIC PRODUCTS

In this paper cationic cyclo-addition reactions have been classified. Some factors affecting the cyclization rates have been shown. There is a similarity between intraand intermolecular interactions of the cationic and nucleophilic centres, 